present for the past 25 days. No history of sexual assault was forthcoming. There were no genital or extragenital warts either in the parents or any of the close family members seen presently or in the past. Local examination revealed a single, asymptomatic, pedunculated, pink coloured, warty papule, $5 \mathrm{~mm}$ in size, situated at the coronal sulcus at 7 o'clock position (fig). There was no regional lymphadenopathy. No other wart was seen on the body. Histology confirmed the diagnosis of condylomata acuminata. Follow up four weeks after the excision biopsy did not show any recurrence.

Genital warts are not uncommon in children. ${ }^{3}$ The reported age of onset varies from one day to 13 years. ${ }^{2}$ Our patient had exclusive involvement of the genitalia without any evidence of anal involvement or extragenital lesions. The exact mode of contracting the infection is not known. Probably, it was a non-sexual mode, a close intimate contact in the past with a person having warts elsewhere. Although genital and non-genital strains of HPV are different, in some cases the wart virus present on the non-genital sites is responsible for the genital lesion. ${ }^{4}$ In most of the reported cases, sexual assault was suspected despite a clear cut history, ${ }^{56}$ but there are

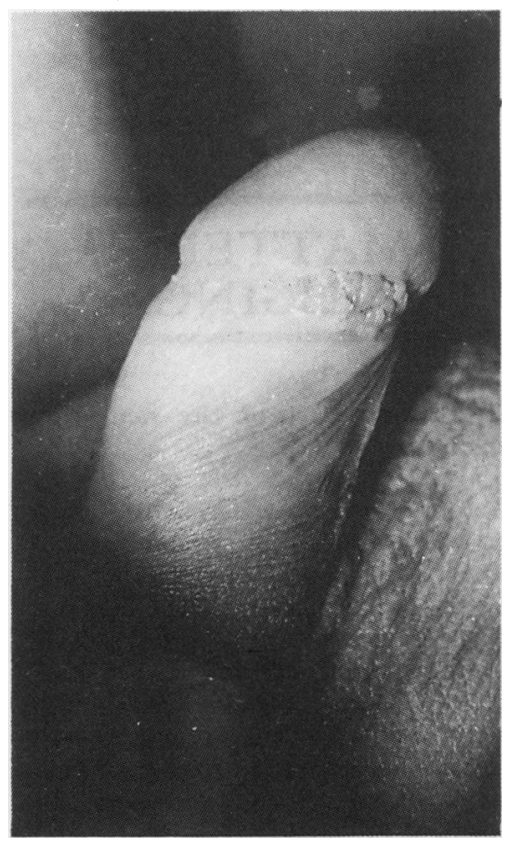

\section{Penicillin concentrations in CSF during repository treatment for syphilis}

Van der Valk et al detected treponemicidal levels of penicillin in cerebrospinal fluid (CSF) after the first daily injection in only 23 of 40 patients treated with daily injections of $2.4 \mathrm{MIU}$ procaine penicillin IM and probenecid $500 \mathrm{mg} 6$ hourly by mouth.

The findings indicate the likelihood that accumulation of penicillin in CSF would occur, to produce higher levels following the second injection of the daily treatment. Thus at $\mathbf{2 4}$ hours after the first injection three of ten patients had treponemicidal levels in CSF. In these patients with treponemicidal levels (and in those with subFigure Penile wort in a 6 year old child. treponemicidal levels), the second injection would produce a concentration of penicillin superimposed upon the existing level from the first injection.

It was for this reason that each penicillin level in our assessment of the regimen for outpatients ${ }^{2}$ was measured after the second to the ninth daily IM injection of procaine penicillin with probenecid by mouth. All our 50 patients had treponemicidal levels in the CSF: 38 after $2.4 \mathrm{MIU}$ daily and 12 after only 1.8 MIU daily: all 50 received probenecid $500 \mathrm{mg} 6$ hourly by mouth. The lowest concentration of penicillin achieved in CSF was $0.06 \mathrm{mg} / 1$ in one of the 12 patients receiving $1.8 \mathrm{MIU}$ procaine penicillin daily, a level providing an appreciable margin. There was no evidence of summation of levels following the second to the ninth injection.

Another difference is that all our patients were ambulant so that the results could be applied to outpatients. Van der Valk et al ${ }^{1}$ tested their patients after complete bed rest following the first injection and considered that they had followed "the same regimen" as we had ${ }^{2}$ although the differences are material.

It is of interest that van der Valk $e t$ $a l^{1}$ found a serum penicillin range of only $0.3-25 \mathrm{mg} / 1$ compared with our $1.5-30.4$ in the 38 patients who had received $2.4 \mathrm{MIU}$ of procaine penicillin G IM daily with probenecid by mouth. The average was $9.1 \mathrm{mg} / 1$ in serum and $0.28 \mathrm{mg} / 1$ in CSF in nine patients over $80 \mathrm{~kg}$ in weight, with a CSF concentration of $3.1 \%$ of serum concentration.

In 8 patients who weighed less than $60 \mathrm{~kg}$ the corresponding levels were appreciably higher at an average 13.8 $\mathrm{mg} / \mathrm{l}, 0.5 \mathrm{mg} / \mathrm{l}$ and $5.5 \%$. So weight may also be a factor in the lower levels found by van der Valk et al. ${ }^{2}$

Previously we had treated 31 patients with an in-patient regimen of 500,000 IU benzyl penicillin G im 6 hourly and probenecid $500 \mathrm{mg} 6$ hourly by mouth. ${ }^{3}$ All were shown to have achieved treponemicidal levels in CSF with this intramuscular regimen.

The work of Fishman ${ }^{4}$ is sometimes quoted against the use of probenecid with penicillin for the treatment of patients with neurosyphilis. But he was considering the use of probenecid in the treatment of "penicillinsensitive bacterial infections" for which high levels of penicillin are indicated at all infected sites; provided 
the treponemicidal level is achieved and maintained there is no evidence that higher levels are more effective against the treponeme.

Fishman ${ }^{4}$ showed, in the experimental animal, that treatment with probenecid in addition to penicillin in equimolecular amounts increased the level of penicillin in the brain by X1.9. This was accompanied by a rather greater increase of X2.9 in plasma, so that the ratio of brain to plasma penicillin decreased from $5 \cdot 4^{\circ}$, to $3.5 \%$.

Probenecid with penicillin or amoxycillin $^{5}$ should be as effective in the treatment of neurosyphilis, providing treponemicidal levels are produced and maintained, as the more complicated intravenous regimens. The matter deserves further examination.

ERIC MC DUNLOP* SAFWAT S AL-EGAILY† ELIZABETH T HOUANG

$\star$ Retired from the Ambrose King Centre (Whitechapel Clinic), The London Hospital, (present address for correspondence: 26 Old School Lane, Milton, Cambridge CB4 4BS, UK †Huddersfield Royal Infirmary; formerly Ambrose King Centre (Whitechapel Clinic), The London Hospital + Department of Medical Microbiology, Queen Charlotte's and Chelsea Hospital; formerly Department of Medical Microbiology, The London Hospital

1 van der Valk PGM, Kraai EJ, van Vôorst Vader PC, HaaxmaReiche H, Snijder JAM. Penicillin concentrations in cerebrospinal fluid (CSF) during repository treatment regimen for syphilis. Genitourin Med 1988;64:223-5.

2 Dunlop EMC, Al-Egaily SS, Houang ET. Production of treponemicidal concentration of penicillin in cerebrospinal fluid. $\mathrm{Br}$ Med J 1981; 283:646.

3 Dunlop EMC, Al-Egaily SS, Houang ET. Penicillin levels in blood and CSF achieved by treatment of syphilis. JAMA 1979;241:2538-40.

4 Fishman RA. Blood-brain and CSF barriers to penicillin and related organic acids. Arch Neurol 1966; 15:113-24.

5 Faber WR, Bos JD, Rietra PJGM, Fass $H$, van Eijk RVW. Treponemicidal levels of amoxicillin in cerebrospinal fluid after oral administration. Sex Transm Dis 1983;10:148-50.

\section{Colposcopy in Teenagers}

The incidence of pre-invasive squamous carcinoma of the cervix

Age distribution against cervical biopsy

\begin{tabular}{lcllclll}
\hline \multicolumn{7}{c}{ Cervical biopsy results } \\
\cline { 3 - 7 } Age & No & $\begin{array}{l}\text { Normal or } \\
\text { inflammatory }\end{array}$ & $\begin{array}{l}\text { HPV } \\
\text { histology }\end{array}$ & CIN 1 & CIN 2 & CIN 3 \\
\hline 15 & 1 & - & - & 1 & - & - \\
16 & 12 & 2 & 5 & 6 & 2 & - \\
17 & 15 & 2 & 5 & 9 & 4 & - \\
18 & 32 & 5 & 15 & 9 & 1 & - \\
19 & 36 & 11 & 39 & 28 & 8 & 1 \\
Totals & 96 & 20 & 15 & 9 & \\
\hline
\end{tabular}

among younger women is increasing steadily in England and Wales. ${ }^{12}$ It has been suggested that these lesions progress rapidly to invasive cancer in younger women. ${ }^{3}$ We screened, cytologically, colposcopically and histologically, 96 teenagers with genital warts for cervical intraepithelial neoplasia, whose mean age was 17.9 (range 15 to 19 years). Seventy $(73 \%$ ) of them were smokers and $69(72 \%)$ of them used an oral contraceptive pill; only $15(15.6 \%)$ used barrier methods. The majority of them were having regular sexual intercourse from the age of 16 and continued to have multiple sexual partners. Histological evidence of cervical intraepithelial neoplasia was found in $37(38.5 \%)$ patients (table).

Epidemiological studies indicate that principal risk factors for cervical neoplasia are early engagement in sexual intercourse, multiple partners ${ }^{4}$ and cigarette smoking. ${ }^{5}$ Recent data have suggested that long term use of oral contraceptive increases the risk of cervical cancer. ${ }^{6}$ It has also been established that a close link exists between cervical intraepithelial neoplasia and human papilloma virus.

The detection of a high incidence of cervical intraepithelial neoplasia among teenagers is rather alarming. Our study has shown that the majority of these teenagers have multiple risk factors for cervical neoplasia. We feel strongly that a colposcopic examination and regular follow-up is mandatory in these groups of patients. Our results support the argument that cervical screening should start from an earlier age than currently recommended.

K SIVAKUMAR
AH DE SILVA
R BASU ROY
Department of Genito-Urinary Medicine
Royal Victoria Hospital,
Gloucester Road,
Bournemouth BH7 6JF, UK

1 Roberts A. Cervical cytology in England and Wales 1965-80. Health Trends 1982;14:41-5.

2 Wolfendale MR, King S, Usherwood $M M$. Abnormal smears; are we in for an epidemic? $\mathrm{Br}$ Med J 1983;287: 526-8.

3 Patterson MEL, Peel KB, Joslin CAF. Cervical smear histories of 500 women with invasive cancer in Yorkshire. Br Med J 1984;289:896-8.

4 Kessler I. Venereal factors in human cervical cancer: evidence from marital cluster. Cancer 1977;39: 1912-9.

5 Harris RWC, Brinton LA, Cowdell RH, et al. Characteristics of women with carcinoma in situ of cervix uteri. $B r J$ Cancer 1980;42:359-69.

6 Beral V, Hannaford P, Kay C. Oral contraceptive use and malignancies of the genital tract. Lancet 1988;ii: $1331-4$.

7 McCance DJ, Campion MJ, Clarkson PK, Chesters PM, Jenkins D, Singer A. Prevalence of human papillomavirus type 16 DNA. Sequence in cervical intraepithelial neoplasia and invasive carcinoma of cervix. $\mathrm{Br} J$ Obstet Gynaecol 1985;92:1101-5.

MATTERS ARISING

Genital warts and the need for screening

Griffiths et al reviewed 100 consecutive women with genital warts to determine the prevalence of associated lower genital tract infection. ${ }^{1} \mathrm{He}$ concludes that screening all women with genital warts for other sexually transmitted diseases, whilst ignoring a similar risk in women without warts, may be inappropriate. In an attempt to assess the situation for ourselves, we looked at 127 consecutive women and 145 consecutive men, presenting dur- 